\title{
Acercamiento a las categorías: profesional en contaduría pública y la cultura, como criterios de análisis en la percepción del contador público
}

\section{Approach to the categories: professional in public accounting and culture, as criteria of analysis in the perception of the public accountant}

Rodolfo Antonio Munevar-Moreno; Mayerly Alejandra Moreno-Bautista²;

Sandra Liliana Castellanos-Zambrano ${ }^{3}$

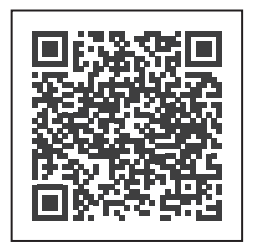

\section{Palabras clave:}

contabilidad, cultura, cine, fotografía, profesión, contador.

Articulo de revisión:

Fecha de recepción: $15 / 04 / 2020$

Fecha de aceptación: 30/06/2020

Esta publicación se encuentra bajo licencia:

Creative Commons

Reconocimiento-

NoComercial-

SinObraDerivada 4.0

Internacional

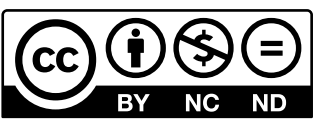

\section{Resumen}

El artículo de revisión está enmarcado dentro del desarrollo de un proyecto de investigación titulado Percepción del profesional en Contaduría Pública desde la fotografía y el cine como expresiones culturales y su objetivo es establecer un acercamiento conceptual a las categorías profesional en Contaduría Pública y la Cultura y dos subcategorías, fotografía y cine, como criterios teóricos de análisis de los resultados de la investigación. El interés se motiva en las reflexiones propias de profesionales y estudiantes en la Contaduría Pública y su relación con la sociedad y la construcción de cultura.

1 Contador público, especialista en Revisoría Fiscal y Contraloría. Tesista para optar al título de magíster en Historia. Estudiante, doctorado en Ciencias Contables, Universidad de los Andes, Mérida, Venezuela. Docente investigador, Grupo RE-DES, programa de Contaduría Pública, Fundación Universitaria Juan de Castellanos, Colombia. rodolfo.munevar@gmail.com, ORCID: https://orcid. org/0000-0003-0617-6819

2 Contadora pública, joven semillero investigador, Grupo de Investigación RE-DES, programa de Contaduría Pública, Fundación Universitaria Juan de Castellanos, Colombia. alejandra12-16@hotmail.com, ORCID: https://orcid. org/0000-0002-1627-2065

3 Contadora pública, joven semillero investigador, Grupo de Investigación RE-DES, programa de Contaduría Pública, Fundación Universitaria Juan de Castellanos, Colombia. sandracastelllanos01@gmail.com, ORCID: https://orcid. org/0000-0001-9212-223X 


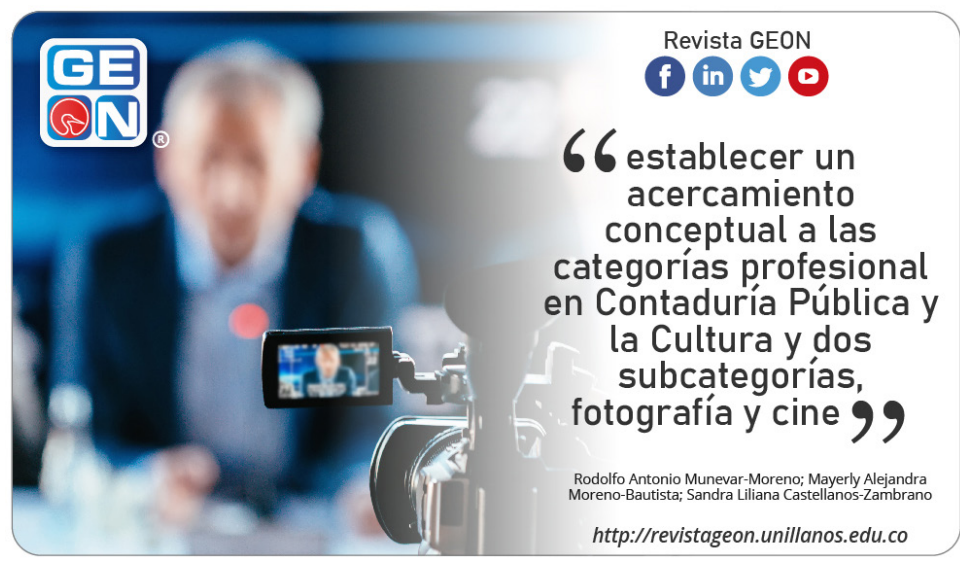

Las revisiones se obtienen principalmente en Google Scholar, repositorios universitarios y parte en bases de datos, como Redalyc, Academia y Scielo. El aporte principal que se logra es la consolidación de la propuesta entorno al profesional en Contaduría Pública y su relación con la sociedad; así como la creación de estereotipos elaborados a partir de herramientas que ayudan a consolidar la cultura, como son la fotografía y el cine.

Palabras claves: contabilidad, cultura, cine, fotografía, profesión, contador.

Códigos JEL: M410 Accounting, M490 Accounting: Other

\section{Abstract}

The review article is framed within the development of a research project entitled "Perception of the professional of Public Accounting from photography and cinema as cultural expressions"; and its objective is to establish a conceptual approach to the categories: Professional of Public Accounting and Culture and two photography and cinema subcategories, as theoretical tools for analysis of research results. The interest is motivated in the reflections of professionals and students in training of the Public Accounting and its relationship with society and the construction of Culture.

Reviews are mostly accomplished in Google Scholar, repositories and part in databases like Redalyc, 
Cómo citar este artículo/

Toreference this article:

Munevar-Moreno, R. A., MorenoBautista, M. A., \& CastellanosZambrano, S. L. (2020) Acercamiento a las categorías: profesional en contaduría pública y la cultura, como criterios de análisis en la percepción del contador público. Revista GEON (Gestión, Organizaciones Y Negocios), 7(2). https://doi. org/10.22579/23463910.208
Academia and Scielo. The main contribution that is achieved is the consolidation of the proposal around the professional of Public Accounting and his relationship with society; as well as the creation of stereotypes elaborated from tools that help to consolidate culture such as photography and cinema.

Keywords: Accounting, Film media, Photography, Professional occupations, Accountant.

JEL Codes: M410 Accounting, M490 Accounting: Other

\section{Introducción}

El desarrollo del artículo pretende establecer un acercamiento conceptual a dos categorías: profesional en Contaduría Pública y la Cultura, y dos subcategorías, fotografía y cine, las cuales se relacionan como herramientas de análisis de los resultados del proyecto Percepción del profesional en Contaduría Pública desde la fotografía y el cine como expresiones culturales, desarrollado dentro del trabajo del semillero de investigación "Otras Realidades de la Contabilidad", del Grupo de Investigación RE-DES en la Fundación Universitaria Juan de Castellanos.

El proyecto surge de la reflexión que se hace acerca de la percepción que tienen varios actores de la sociedad sobre la contabilidad y el profesional en contaduría pública, donde lo cultural, como concepto transversal, puede ayudar a comprender la imagen o los estereotipos que se crean alrededor de un profesional que tiene gran relevancia en la sociedad.

En el desarrollo del contenido se logra hacer un acercamiento a la relación entre los conceptos Profesional en Contaduría Pública y la Cultura, y dos subcategorias fotografía y cine, que en principio no es clara por la limitada publicación de textos como artículos de investigación, libros y proyectos de pregrado y posgrado; sin embargo, se logra establecer una mayor viabilidad del proyecto principal al encontrar autores que se acercan al tema y dan base teórica para su continuación.

Aunque no se encuentran de manera sistemática estudios centrados en el tema principal, es posible ver en la revisión hecha que no solo los profesionales en Contaduría Pública hablan sobre su práctica y ejercicio dentro de la sociedad, sino que existen las miradas de otros profesionales que proponen acertadamente un papel del profesional en Contaduría en lo social y económico.

El documento se estableció en dos títulos principales de acuerdo con las categorías propuestas para revisar: el primero, el Profesional en Contaduría Pública, donde se relacionan estudios con aspectos como las habilidades, las competencias, la posición de po- 
der o la construcción propia de la profesión; el segundo título desarrolla los conceptos de la Cultura, cine y fotografía, incluyendo un título donde relaciona algunos estudios previos que se han acercado al tema del proyecto principal y de la revisión de textos realizada como base para el análisis y la comprensión de los resultados.

\section{Materiales y métodos}

La revisión se orientó desde el proyecto de investigación titulado Percepción del profesional en Contaduría Pública desde la fotografía y el cine como expresiones culturales. Principalmente se llevaron a cabo búsquedas en Google Scholar, repositorios de trabajos de pregrado y posgrado de las universidades nacionales e internacionales y bases de datos como Redalyc, Academia y Scielo, en un período de un año. Fueron revisados 60 documentos entre artículos, libros, trabajos de pregrado y grado.

La selección de los documentos fue realizada teniendo en cuenta el aporte que podían hacer a la construcción de las categorías del profesiónal en Contaduría Pública y la Cultura, así como a sus dos subcategorías, fotografía y cine, con las cuales se realizó un análisis posterior a la información obtenida en los instrumentos para el proyecto principal.

\section{Contexto teórico}

El texto como artículo de revisión propone en su desarrollo y discusión elementos teóricos desde las dos categorías principales: el Profesional en
Contaduría Pública y la Cultura, que aportan al proyecto principal, titulado Percepción del profesional en Contaduría Pública desde la fotografía y el cine como expresiones culturales. El interés principal es encontrar los conceptos de categorías como profesional de la Contaduría Pública, donde se retoman autores como Ariza (2012), Martínez (1993), Giraldo (2013), Ortiz (2011), entre otros, que establecen elementos de la evolución de la contabilidad en su práctica, así como acercamientos al concepto desde sus habilidades, competencias y formación.

Otra categoría es la Cultura, donde se incluyen autores como Muñoz (2005), Geertz (2003), Giménez (2007) y Rios (2013), quienes establecen una pluralidad en la construcción y enfoque del concepto de Cultura, pero que ayudan y aportan en el análisis y relación con las otras categorías.

\section{Desarrollo y discusión}

En el desarrollo de la revisión de textos para la primera fase de la investigación se estableció la necesidad de categorías que lograran apoyar la reflexión de la percepción de un profesional dentro de las organizaciones, como lo es el contador público; por tanto, se propuso la estructura de acuerdo con las categorías de Cultura y subcategorías: fotografía y cine relacionadas con el Profesional en Contaduría Pública.

\section{Profesional en Contaduría Pública}

La categoría principal dentro de la investigación la constituye la Contadu- 
ría Pública como profesión, que, a la vez, es el objeto de estudio que se relaciona con las otras categorías, como la Cultura, y los elementos que la enriquecen, como la fotografía y el cine. Lo primero es establecer acercamientos a la contabilidad como conocimiento eje y al profesional en Contaduría Pública o contador público.

\section{La contabilidad y el contador público}

Es importante mencionar, inicialmente, que la contabilidad es un conocimiento propio de la sociedad que se relaciona con la historia y la economía; para soportar lo anterior, es posible retomar a Ariza (2012), quien afirma que "el primitivo concepto de contabilidad evolucionó a la par con los distintos acontecimientos socioeconómicos que en una u otra forma actuaron siempre determinantemente en el desarrollo histórico de la actividad contable" (p.9).

Además, los acontecimientos socioeconómicos vistos de manera micro permiten identificar actores como las organizaciones, que son parte de los fenómenos expresados por Ariza (2012), las cuales han tenido beneficios del conocimiento contable, ya sea desde su aplicación o su teorización, situación que resalta Martínez (1993), que expresa que, no solo con el papel de la contabilidad, sino con el desarrollo de la profesión, la Contaduría Pública nace como profesión a partir de una serie de necesidades de la organización y del desarrollo económico, donde lo que se buscaba era lograr el reto de construir y consolidar un modelo contable. De igual manera es posible complementar lo expuesto al decir que la profesión del Contador Público ha venido evolucionando con la creación de nuevas técnicas contables (Giraldo, 2013).

Otra mirada que se encuentra acerca de la profesión contable desde su ejercicio es la presentada por Ortiz (2011), quien menciona que su función en las organizaciones está entre "la de economizarles un tiempo precioso llevándoles las cuentas, o la de revisar sus desvencijados presupuestos o tramar sus evasiones tributarias", situación que complementa afirmando dentro de su texto que "el saber contable es algo rutinario e intrascendente" (p.62), cuyo conocimiento está basado en normas repetitivas, que, de esta manera, logran un saber estratégico.

Por otra parte, el perfil del profesional en Contaduría Pública siempre se relaciona con la integridad en el momento de ejercer sus funciones profesionales, así como "el aporte que el Contador Público puede hacer desde su posición al mejoramiento de la estructura de control y a los procesos de administración y gestión de riesgos de la empresa pública y privada" (Orjuela, 2002, p.22); además, se suman expectativas donde "el mercado actual exige de un profesional capaz de entablar diálogo, realizar propuestas concretas y basadas en la realidad económica porque establece relaciones entre su conocimiento y el entorno en el cual se desempeña" (Álvarez, 2018, p.29). 
En relación con lo anterior, es claro que el profesional en Contaduría Pública establece una percepción alta con lo ético. Autores como Alpentista et al. (2011) destacan que "una personalidad ética tiene relación directa con el debido conocimiento sobre las funciones y responsabilidades de la profesión, además del conocimiento de las normas éticas que la rigen, y promueven un actuar acorde a lo que se reconoce como correcto a nivel profesional" (p. 90).

Otros aspectos encontrados en la revisión de la categoría del profesional en Contaduría Pública y que ayudan a comprender la percepción en su entorno son las relacionadas con la formación, la posición de poder, las habilidades y competencias y la capacidad crítica; por tanto, a continuación, se referencian autores que tratan en sus textos los temas mencionados anteriormente.

En lo referente a la formación competitiva, Torres (2012) establece que la práctica profesional es clave para la formación competitiva del contador público, la cual "propende por una alta calidad profesional" (p.45). Asimismo, el contador público debe basarse en normatividad y valores éticos que mejoren el desarrollo de su integridad y su imagen profesional ante la sociedad.

Lo anterior puede ser relacionado con lo que afirman Cardona y Zapata (2003) sobre las habilidades interpersonales, las cuales capacitan "al contador profesional para trabajar con otras personas para el bien común de la organización", así como "las habilidades en la comunicación capacitan al contador profesional para recibir y transmitir información, juzgar en forma razonada y tomar decisiones en forma efectiva" (p.14).

Sobre las competencias, se encontró al autor Cañas (2011), quien indica que "deben ser permanentemente mejoradas y readquiridas considerando que el conocimiento del contador público contiene tanto aspectos tácitos como explícitos que interactúan permanentemente" (p.99). Seguidamente expresa que la profesión en Contaduría Pública es una "cadena de transformación del saber que da lugar a una disciplina del conocimiento" donde se logra pasar de un oficio a una profesión "gracias a la actividad de convertir conocimiento tácito en explícito" (Consejo Técnico de la Contaduría Pública, 2009, p.2).

Para el caso del tema de la "posición de poder", en la que se encuentra el profesional en Contaduría Pública, Aquel et al. (2016) afirman que "la información financiera se volvió cada vez más sofisticada y que a la contabilidad le toca dirigir y controlar ese caudal de información producido en las empresas o entes gubernamentales, el profesional contable termina ocupando una posición de poder" (p.14).

La posición de poder puede ser vista desde la relación con su entorno y sus mismos colegas. En Colombia, a partir de procesos como la implementación del modelo de normas internacionales de información financiera, se establecen puntos de vista, unos a 
favor del empoderamiento social de los profesionales de la Contaduría Pública y sus organismos colegiados y otros en contra, donde se expresan situaciones tales como "en términos generales, la profesión contable se encuentra algo fracturada, ya que la mayoría de los organismos profesionales se encuentran mal equipados para la adopción de normas internacionales" (Martínez et al., 2016, p.8), lo que también aporta a generar dentro y fuera de la profesión elementos para la percepción de instituciones, organizaciones, otros profesionales y personas del común.

Por último, se encontró la necesidad de un profesional en Contaduría Pública más allá de lo practico; así, por ejemplo, Duque (2014) propone: "en este sentido, se considera que una formación de contadores, desprovista de contexto [sin tener en cuenta la realidad] y de pensamiento crítico [sin la sensibilidad por lo otro y el propósito transformador], es una formación profesionalizante, a-histórica y sin mayor meta de compromiso social, una formación que niega, en esencia, la integralidad" (p.19).

\section{La formación del profesional en Contaduría Pública}

La formación del profesional en Contaduría Pública es un elemento clave que debe tenerse en cuenta, en especial para el desarrollo de la revisión propuesta. Autores como Marín et al. (2018) indican que "la formación del contador que se requiere en los momentos actuales debe tener un sen- tido cultural integrador que no solo contribuya a la apropiación de los conocimientos propios de la profesión para garantizar la competitividad de las empresas" (p.2). Sin embargo, tal como lo indica Mendoza (2010) citado por Marin (2018), la formación en la profesión contable no solo debe contribuir a tener conocimientos propios, sino debe ser un profesional que esté regido bajo principios éticos, donde logre un "proceso de transmisión y asimilación de los aportes esenciales de la cultura universal" (p.5).

Desde la formación del profesional contable se hace necesario que se tenga un amplio conocimiento normativo de los tratamientos contables que se han venido teniendo y cambiando con el paso del tiempo, con un actuar propio coherente, los cuales estén bajo la formación de valores adquiridos y las exigencias que la sociedad pide, de tal manera que se propicie una buena imagen del profesional contable en el ámbito laboral, social, cultural y familiar y, como indica Torres (2012), "desde la concepción educativa se debe tener una realidad económica y socio-política del campo contable" (p.39).

Las propuestas de los diversos autores relacionan al profesional en Contaduría Pública con diversos contextos, su ejercicio no se limita a las organizaciones donde pone en práctica su conocimiento, sino que es provisto de una serie de cualidades y características intrínsecas que son percibidas de manera directa o indirecta por otros profesionales o por la misma sociedad. 
De acuerdo con los autores, el contador público está provisto de habilidades y competencias profesionales y personales. Es claro que al profesional en Contaduría Pública se le relaciona con lo social y que su práctica genera impacto en la sociedad, por lo cual podemos concluir que hace parte de la construcción de cultura en sus entornos.

Otro aspecto que debe resaltarse es la percepción que se establece por parte de los autores, ya sea de experiencias y prácticas propias o a través de estudios previos o experiencias de terceros, situación que sigue reafirmando la necesidad por comprender la percepción que tienen otros del profesional en Contaduría Pública en la sociedad y cómo se hace partícipe en la construcción de la cultura en sus contextos.

\section{Cultura}

En la evolución de la humanidad se observa al conocimiento como un elemento clave y base de las sociedades; asimismo, todos los rasgos generados a partir de su experiencia han hecho parte de la construcción propia como personas y comunidad; cualquier profesional está inmerso dentro de alguna comunidad, lo cual determina la cultura a la que pertenece. Por lo anterior, es importante realizar un acercamiento a esta categoría que se utilizó para la compresión de los resultados de la investigación posteriormente.

Lo primero que se encuentra sobre la Cultura como concepto son las múl- tiples acepciones, "las concepciones sobre el concepto y sentido de lo que debe entenderse por cultura son tan diferentes e incluso antagónicas que a menudo parecen referirse a procesos incompatibles" (Muñoz, 2005, p.295).

Un primer acercamiento se realiza desde autores que lo presentan como un fenómeno; por ejemplo, Salgado (2016) define que "la cultura es un fenómeno complejo y está relacionada con la vida en sociedad [la cual] se materializa en contextos y tiempos determinados que son determinantes de la misma cultura" (p.104). Lo anterior se puede complementar con lo que se retoma en la editorial de la Revista Marina (1983), donde se dice que ese fenómeno "es el conjunto de valores, creencias, logros intelectuales, manifestaciones artísticas y técnicas generalizadas que caracterizan a una determinada sociedad o civilización"; es decir, según Geertz (2003), cada sociedad crea sus diferentes conceptos de cultura de acuerdo con el sistema de concepciones heredadas, donde el hombre se comunica y desarrolla su conocimiento y sus actitudes frente a la vida.

Por otro lado, se tienen autores que toman la Cultura desde el sujeto, por ejemplo, un autor como Giménez (2007) señala que "la cultura es la organización social del sentido, interiorizado de modo relativamente estable por los sujetos en forma de esquemas o de representaciones compartidas, y objetivado en 'formas simbólicas', todo ello en contextos históricamente específicos y socialmente estructurados" (p.5). Además de dar origen 
al concepto desde el sujeto, también se apropian a la cultura características desde este para poderla definir; por ejemplo, Hofstede (1984) citado por Ríos (2013) define "la cultura como una programación colectiva de la mente, difícil de cambiar, que distingue a un grupo de personas de los demás" (p.16).

Es posible que, al seguir revisando otros autores, el concepto de cultura sea visto desde varias posiciones, ya sea por la ideología, la experiencia, la profesión o el entorno; pero es claro que la cultura como categoría y concepto puede ayudar a comprender la percepción que se tiene del profesional en Contaduría Pública.

\section{Contabilidad relacionada con la cultura}

Para el caso objeto de la investigación, del cual hace parte la primera fase de revisión, era necesario establecer esa relación entre el concepto de cultura y la disciplina eje de la profesión del contador público.

De lo anterior, la relación cultura y contabilidad, Ocampo (2008), en su artículo Algunas relaciones entre contabilidad y cultura, cita a Warley (2003) estableciendo que "la cultura ha sido reconocida como herencia social de la humanidad, ya que va irradiando unas normas de conducta, costumbres, hábitos, tradiciones [y] conocimientos" (p.18).

Desde las diferentes épocas de la historia se ha venido creando diferentes expectativas y realidades referentes a la profesión de la contaduría pública, todo esto enmarcado en un ámbito cultural donde se captan diferentes aspectos tanto económicos como sociales.

En la antigüedad no se conocía el concepto de contador público, pero aun así se usaban técnicas de conteo, la sociedad se preocupaba desde esos tiempos por la tesorería; es decir "la contabilidad no es un conocimiento estático sino dinámico y va evolucionando en la medida que se desarrolla el conocimiento humano" (Burbano, 1989). Mientras que la contabilidad va cambiando el profesional contable en el ámbito laboral va evolucionando de acuerdo con los cambios que la sociedad va teniendo.

La Cultura y la Contaduría Pública mantienen una conexión; la una influye en la otra. Al respecto, Ocampo et al. (2008, p. 247), en lo que concierne a la relación entre contabilidad y cultura, señalan que "la contabilidad no es ajena a la sociedad en la cual se desarrolla y el contador trabaja y elabora procesos contables y cognitivos en busca de satisfacer las necesidades de información y avanzar disciplinalmente". Además, se puede complementar con lo afirmado por Ospina (2006, p. 160), quien señala que el contador está inmerso en relaciones con otras disciplinas y su profesión participa de manera activa, por ejemplo, en la responsabilidad social de las organizaciones.

Ahora existen herramientas dentro de las sociedades que por la evolución del conocimiento científico generado 
logran que la cultura sea apropiada de una forma u otra por las diferentes sociedades. Su intervención hace que se masifiquen imágenes, estereotipos y costumbres o, por el contrario, que se anulen en función de intereses económicos, políticos o sociales.

Para el caso tomamos a la fotografía y al cine, que denominamos subcategorías que pueden aportar en la construcción de la percepción del profesional en Contaduría Pública.

\section{Fotografía}

La fotografía se estableció como una subcategoría de la Cultura dentro de la investigación, como criterio para analizar la percepción del contador público como profesional. Se propone como la aplicación de conocimiento multidisciplinario en función de mantener en el tiempo la memoria de sucesos, momentos, lugares que son parte de la construcción de la cultura.

Ahora, las representaciones en imágenes han sido parte importante para la creación de estereotipos culturales y sociales que han dado sentidos múltiples: como fuente de datos, como objetos de estudio, como indicios culturales; por medio del uso de la fotografía se hace la construcción y transmisión de experiencias en una temporalidad determinada; a través de la representación de imágenes se dan múltiples sentidos en cada época

Según Jelin (2011), "las fotografías actúan como estímulo para la reflexión sobre la situación social en general, la situación personal y familiar; asimis- mo, se expresan ilusiones y desilusiones, experiencias vividas y horizontes de expectativas" (p.57). Por lo anterior, la representación de imágenes por medio de fotografías hace que la sociedad tenga diferentes percepciones y se creen diferentes estereotipos; la misma autora indica "la imagen es el estímulo que produce memorias de situaciones vividas que pueden haber sido similares a las que muestra la imagen" (p.63).

La percepción obtenida a través de la observación de fotografías hace que surjan varias preguntas acerca de la representación. Las fotografías se convierten en un estímulo abierto que da pie a recuerdos, elaboraciones del presente y expectativas de futuro que no están en la fotografía misma.

A través de las fotografías la sociedad puede generar diferentes conceptos de tipo abierto o cerrado. Sontang (1973) expresa que las fotografías "son en efecto experiencia capturada y la cámara es el arma ideal de la conciencia en su talante codicioso, donde fotografiar es apropiarse de lo fotografiado, significa establecer con el mundo una relación determinada que parece conocimiento $\mathrm{y}$, por lo tanto, poder" (p.16).

A través de las fotografías se acumula y se almacena fácilmente en nuestras memorias la percepción; es de esta manera como logramos obtener y crear diferentes estereotipos.

\section{Cine}

Otra subcategoría utilizada dentro de la investigación y que hace parte de 
la construcción moderna en la cultura es el cine, el cual es la aplicación de conocimiento también multidisciplinario. Según afirma Guber (1969), "el cine es, como la fotografía y el fonógrafo, un procedimiento técnico que permite al hombre asir un aspecto del mundo: el dinamismo de la realidad visible". Importante aporte al relacionarlo no solo como una técnica, sino como una ventana al "mundo", según expresa el autor.

También se puede decir que el cine ha influido en la percepción de la realidad y de los elementos que la constituyen en el mundo, entre las cuales están las diferentes actividades realizadas por el ser humano, incluyendo las profesiones; lo anterior es concordante con lo expuesto por Stein et al. (2010), quienes afirman:

El cine ha pretendido convertirse en una manifestación artística más, por lo que ha tratado todos los problemas y temáticas que rodean la vida de los hombres. De alguna manera ha intentado responder a las necesidades e inquietudes del ser humano; ha provocado miedo, compasión, ternura [y] comicidad [...] y este, a su vez, ha respondido a diversas situaciones sociales. (p. 11)

Lo anterior hace ver al cine como una importante herramienta para obtener la percepción del profesional en contaduría pública y cómo a través de sus imágenes y sonidos ha logrado establecer patrones o estereotipos alrededor de su práctica y relación con la sociedad.

\section{Percepción del profesional en Contaduría Pública}

La profesión contable ha estado en una constante evolución, ha creado una serie de imaginarios sobre la realidad en la que se desempeñan profesionalmente; por ejemplo, Machado (2007) afirma que:

Las profesiones definen una serie de patrones y modelos de comportamiento, entre estos los que definen las preferencias por la forma de concebir la realidad, los imaginarios, modelos y representaciones del objeto que demarcan el dominio de discurso y el campo de trabajo. (p. 86)

Dentro de este mismo contexto, Machado (2007) define un imaginario como "una referencia a imágenes que representan el mundo, representar es evocar, construir con sentido una imagen de un mundo real" (p.81). El imaginario del profesional contable de cierta manera influye como un indicador clave de la evolución en las trasformaciones de los servicios que el contador público desempeña en la sociedad.

Así mismo, fue posible encontrar profesionales que han intentado abordar el tema de manera directa o como parte del análisis dentro de estudios que se acercan al profesional en Contaduría Pública; a continuación, se relacionaran algunos de los autores encontrados dentro de la revisión realizada.

Para Dimnik y Felton (2006), citados por Splitter y Borba (2014): 
[...] el contador es uno de los profesionales que más se ha preocupado, en los últimos años, por la imagen pública; proponen que durante años se han visto con la imagen de una persona antipática y poco atrayente; siempre forzados a defenderse contra acusaciones, esforzándose en su reputación de competentes e íntegros. (p.127)

Otros, como Renato (2012), mencionan que "la profesión contable carece de proyección de una imagen de confianza, respetabilidad y de ofrecer desafíos, recompensas y perspectivas, con el fin de atraer y retener a los estudiantes y profesionales más talentosos, éticos y competentes" (p.23). Asimismo, los autores encuentran recurrentemente un comportamiento ético positivo de los contadores retratado en el cine, asociado a características intrínsecas y valores y negativamente asociados a sus competencias y valores instrumentales.

El cine ha influido de manera positiva y negativa en el desarrollo de la historia y de las acciones del ser humano, caracterizado, por un lado, para generar emociones y sentimientos y, por el otro, generar un impacto de conciencia de la propia realidad (Rovira, 2013). Dentro de las percepciones de las imágenes creadas y transmitidas por este medio se ha creado una serie de estereotipos a favor y en contra del contador público en sus diferentes roles sociales.

Por ejemplo, Pinto (2011), en un conversatorio con otras dos profesionales en Contaduría Pública, realizan un aná- lisis del papel del cine en la contabilidad y la profesión, donde se exponen ideas de cómo el contador en el marco de las películas se presenta como:

Un personaje muy serio, muy plano, casi invisible, con gafas, muy gris, a veces como ya canosito, escondido en el último rincón de la organización en la que se encuentra, supremamente psicorrígido; eso me parece preocupante. Digamos que no puede ir más allá de la exactitud de los números y eso nos preocupa. (p. 610)

Con lo anterior es posible atreverse a decir que por medio del cine y de las imágenes presentadas en el mismo, la sociedad ha venido creando una identidad que representa al contador público como profesional en el desarrollo de sus funciones y prácticas.

Otra idea que se puede dar es que la profesión contable es un ejercicio que impacta directamente el imaginario social, pero se acentúa más con los papeles dentro de las películas. Para el caso, Valero y Barrios (2012), a partir de la revisión de películas comerciales hasta el año 2000, identificaron cinco estereotipos del contador en el cine: soñador, trabajador dedicado, excéntrico, héroe y villano.

Lo anterior son trabajos que se han realizado de manera exploratoria sin lograr ahondar dentro del análisis de contenido que debería darse a las películas para establecer de manera más científica esa imagen proyectada y cómo pudo influenciar durante épocas en la sociedad, porque de cierta 
manera no se reconoce la responsabilidad del contador público en la sociedad, el uso de sus conocimientos contables y los posibles estereotipos del profesional en contaduría pública en las culturas.

\section{Almario (2013) expresa:}

En el cine encontramos muchas características que ha desarrollado el contador público como lo son personas de oficina muy bien vestidas, muy aptas en manejo de los números de la empresa y en la liquidación de impuestos; además de ser personas oscuras bajo una gran tensión por la responsabilidad y la confidencialidad de la información que manejan. (p. 17)

Asimismo, autores como Novoa (2017) expresan que se viene formando y reproduciendo un patrón respecto a la imagen del contador público en el cine. A pesar de que los filmes seleccionados en su estudio transcurren a lo largo de treinta años, hay características que siguen permaneciendo y reflejan una imagen común del profesional, lo que genera que en el público se sigan perpetuando estas ideas.

De lo anterior es posible indicar que existen patrones e imágenes del profesional en Contaduría Pública que se incrustaron dentro de la sociedad y su cultura. Esta realidad es abordada desde otros conceptos que pueden ayudar a mejorar la comprensión de cómo se ve al profesional; por ejemplo, Splitter y Borba (2014) expresan que:

Los estereotipos surgen del proceso cognitivo de formar percep- ciones sobre grupos de personas, normalmente involucrando la atribución de rótulos para esos grupos. Esos rótulos son llamados "Estereotipos". Así pues, este estereotipo serio, de forma simple, la idea sobre algo o alguien, la imagen espontánea que surge en la mente cuando el individuo se depara con determinadas situaciones. (p.129)

Algunos de los factores anteriormente mencionados han hecho que la profesión contable haya mermado su credibilidad y generado estereotipos diferentes. Lo anterior se agrava con la fotografía publicada en medios de comunicación y redes sociales y las películas creadas acerca del profesional.

También es pertinente mencionar que dentro de la revisión se propone un debate sobre el actuar del profesional en Contaduría Pública y cómo existen varios factores que influyen en sus actos como profesional, así como lo es la relación de poder, lo cual implica externalidades tanto positivas como negativas. En concordancia Bauman (2011), citado por Giraldo (2013, p.671), se piensa que "el profesional contable está influenciado por ciertas fuerzas propias de la dinámica empresarial, como la racionalidad instrumental, el facilismo, el hedonismo, el narcisismo, el individualismo y las relaciones de poder, entre otras, derivadas del pensamiento moderno y posmoderno", tal vez fuerzas propias no del profesional en Contaduría Pública sino de la cultura y en especial del modelo económico actual que rige dentro de esta. 


\section{Conclusiones}

El profesional en Contaduría Pública ha evolucionado en la historia a causa de factores sociales, económicos y políticos, que tienen una gran relación con las organizaciones que son el centro de la economía. Con su práctica y ejercicio dentro de la sociedad es reconocido por características personales como la responsabilidad, la ética, la integridad y la disciplina $y$, como profesionales con preparación, formación y competitividad. Lo anterior ha hecho que alrededor del profesional en Contaduría Pública se creen estereotipos que tienen su origen en la percepción de otros integrantes de la sociedad, a veces inmutable durante épocas, reforzado muchas veces por herramientas de construcción de cultura como lo son la fotografía y el cine.

La categoría cultura se propone como una categoría transversal, principal para lograr entender, ya sea desde el sujeto o como fenómeno, la percepción que se genera de la práctica y ejercicio del profesional en Contaduría Pública. Con acercamientos teóricos es posible develar su contribución en la construcción de una parte de la cultura, en especial al nivel micro dentro de las organizaciones tanto privadas como públicas; hasta es posible que un acercamiento teórico logre que se entienda la percepción propia de estudiantes en formación y de los mismos profesionales.

La fotografía y el cine, que se denominan en el proyecto herramientas de construcción como elementos teóri- cos, se proponen con el objetivo de abordar y construir la percepción sobre el profesional en Contaduría Pública de otros actores de la sociedad y de los mismos profesionales. Como se mencionó, no solo es aplicación de conocimiento multidisciplinar, son construcciones de la sociedad para representar momentos o lapsos de memoria retratados desde ópticas con fines políticos, sociales o económicos, pero que develan a la par otros aspectos importantes como las prácticas, los sentimientos y los actores de épocas de la historia de la humanidad en la cuales ha estado inmerso el profesional en Contaduría Pública.

\section{Referencias}

Almario, C. (2013). Imagen social de los profesionales contables a partir de las representaciones graficas (caricaturas) aparecidas en publicaciones gremiales norteamericanas [tesis de pregrado, Universidad Militar Nueva Granada]. Repositorio Universidad Militar Nueva Granada. https://bit.ly/3qC39HY

Alpentista, M., lasuozzi, M., \& Merin, M. (2011). La ética profesional y el contador público. Universidad Nacional de Cuyo. Mendoza. https://bit.ly/3mIWpFJ

Álvarez, F., Iriarte, M., \& Romero, A. (2018). Perfil profesional y modelos de formación del contador público atendiendo a las NIIF [tesis de grado, Universidad Cooperativa de Colombia]. Repositorio Universidad Cooperativa de Colombia. https://bit.ly/2VAm8Er

Amador, P. (2004). La imagen fotográfica y su lectura. Editorial Archiviana. https://bit.ly/3oglHeG

Aquel, S., Cicerchia, L., Fernández, A., Foresti, C., Navarro, D., \& Rodoreda, T. 
(2016, noviembre). La profesión contable y su relación con el capitalismo global [presentación]. Vigésima Primera Jornadas "Investigaciones en la Facultad" de Ciencias Económicas y Estadísticas. https://bit.ly/3qqgXFI

Ariza, B. (2012). La contabilidad como expresión sociocultural: una reflexión histórica. Revista Visión Contable, (10), 79-116. https://bit.ly/3mAnrz0

Ascencio, N., Gallego, L., \& Solórzano, O. (2017, 27-29 de septiembre). Estrategia para la apropiación del conocimiento de la cultura contable en Colombia [ponencia]. XXII Congreso Internacional de Contaduría, Administración e Informática. https://bit. Iy/3mGhgJU

Aponte, F. (2012). Papel del contador público en Colombia desde la época colonial hasta el 2012 [tesis de grado, Universidad de San Buenaventura]. Repositorio Universidad de San Buenaventura. https://bit.ly/3lGmRyk

Benítez, C, (2016). Ética y mala praxis del contador público en la provincia de Córdoba [tesis de grado, Universidad Siglo 21]. Repositorio Institucional Universidad Siglo 21. https://bit. ly/36Gd8Ed

Burbano, J. (1989). Contabilidad: análisis histórico de su objeto y su método. Pliegos Administrativos y Financieros, 12(35). https://bit.ly/2VxfJKh

Cañas, S., Castaño, V., \& Tamayo, H. (2011). El contador público y su proceso de formación ética y social. Revista Visión Contable, (9), 97-106. https://bit. ly/3ohLBi4

Cardona, J., \& Zapata, M. (2003, 16-18 de octubre). Estándares internacionales para la formación del contador público [ponencia]. XX Simposio sobre
Revisoría Fiscal "La Revisoría Fiscal y la internacionalización del concepto contable", Medellín, Colombia. https:// bit.ly/3ot0819

Consejo Técnico de la Contaduría Pública. (2009). Orientación profesional: tarifas de honorarios profesionales. https://bit.ly/3g7UOGU

Correa, J. (2006). Algunas reflexiones en torno a la interacción de los contadores públicos en las pequeñas empresas. Contaduría Universidad de Antioquia, (49), 71-86. https://bit.ly/39IZKku

Cuartas, J. (2015). Percepción hacia el contador público como influyente en su campo de acción. Trabajos de Grado Contaduría Pública, 9(1). https://bit. ly/3mlHLhB

Díaz, J., Parrado, W., Moya, S., Saénz, K., \& Cepeda, M. (2016). Perfil profesional del revisor fiscal y el auditor respecto a la NIA 500. Revista GEON (Gestión, Organizaciones y Negocios), 3(2), 6-13. https://bit.ly/33J9180

Duque, O., Pinzón, J. (2014). Pensar el currículo: En la búsqueda de sentidos para la formación integral de contadores públicos. Revista Lúmina, 15(1), 174-201. https://bit.ly/33M8ORY

Fernández, J. (2001). Elementos que consolidad al concepto profesión. Notas para su reflexión. Revista Electrónica de Investigación Educativa, 3(2), 23-39. https://bit.ly/36Dg7NC

Geertz, C. (2003). La interpretación de las culturas. Editorial Gedisa. https://bit. ly/2KXOwZV

Giménez, G. (2007). La cultura como identidad y la identidad como cultura. Instituto de Investigaciones Sociales de la UNAM, 1-27. https://bit.ly/3/HsyMH 
Giraldo, G. (2013). Aproximación a la relación entre aspectos sociológicos del poder y la ética profesional del contador público. Cuadernos de Contabilidad, 14(35), 669-697. https://bit. ly/39G6u2D

Gubern, R. (1969). Historia del Cine. Editorial Anagrama.

Jelin, E. (2011) La fotografía en la investigación social: algunas reflexiones personales. Revista Memoria y Sociedad, 16(33), 55-67. https://bit.ly/2JR1 ayj

Leitão, R. (2012). Ética Profesional Contable: Un Análisis Visual de la Percepción Pública. Revista de Educação e Pesquisa em Contabilidade, 6(1), 2038. https://bit.ly/2Icnhiv

López Rovira, J. (2013). El estilo cinematográfico y el concepto de autoría en el cine posmoderno: el caso de Fernando Meirelles. Universidad Politécnica de Valencia. https://bit.ly/3IIOA1v

Machado, M. (2007). La responsabilidad social corporativa como resultante de un cambio en los imaginarios del contador público: del mecanicismo a la complejidad de las organizaciones. Contaduría Universidad de Antioquia, (51), 65-88. https://bit.ly/33EopD1

Marín, R., Cabrera, O., \& Torres, A. (2017). El pensamiento económico martiano y la formación de la cultura de los contadores. Revista Científico-Metodológica, (66), 1-9. https://bit.ly/39CDc4V

Marín-Reyes, R., Cabrera-Elejalde, O., \& Torres-Alonso., A. (2018). El pensamiento económico martiano y la formación de la cultura de los contadores. Revista Científico-Metodológica, (66), 1-9. https://bit.ly/2L8AYQA

Martínez, G. (1993). Aproximación histórica al desarrollo de la profesión contable en Colombia. Contaduría Universidad de Antioquia, (23), 65-82. https://bit.ly/391x76Q

Muñoz, B. (2005). Modelos culturales Teoría sociopolítica de la cultura. Editorial Anthropos.

Ocampo, C., Lastra, C., \& Gómez, J. (2008). Algunas relaciones entre contabilidad y cultura. Contaduría Universidad de Antioquia, (52), 251-258. https://bit. ly/2lbQSsd

Orjuela, R. L. (2002). la contribución del contador público en la erradicación de la corrupción. Apuntes Contables, 3, 7-24. https://bit.ly/33EpU47

Ortiz, C. (2011). El contador y la investigación. Cuadernos de Administración, 10(14), 62. https://bit.ly/2Lby6CF

Ospina, C. (2016). Las tramas de la contabilidad: Trazos para quienes empiezan su formación en Contaduría Pública. Contaduría Universidad de Antioquia, (48), 155-186. https://bit.ly/2JR50aH

Panaia, M. (2008). Una revisión de la sociología de las profesiones desde la teoría crítica del trabajo en la Argentina. Comisión Económica para América Latina y el Caribe. https://bit. ly/39E37t3

Pérez, C. (2012). Los contables en el cine. Cont4b/3, (43), 36-37. https://bit. ly/33ErXVR

Pérez Paredes, A., Torralba Flores, A., \& Cruz de los Ángeles, J. A. (2019). Propuestas para fortalecer la cultura emprendedora en los municipios de Puebla y Tlaxcala. Revista GEON (Gestión, Organizaciones Y Negocios), 6(2), 37-51. https://doi. org/10.22579/23463910.172

Pinto, J. (2011). En torno al cine y la contabilidad. Cuadernos de Contabilidad 12(31), 603-617. https://bit.ly/2VC6NTL 
Revista Marina (1983). Profesión y cultura. Revista Marina, 100 (756). https:// revistamarina.cl/revistas/1983/5/editorial.pdf

Ríos, C. (2013). Efecto del conocimiento cultural en la percepción de los auditores: controles internos y fraude. Universidad de Puerto Rico. https://bit. ly/2VBZGL5

Rojas, M., \& Pirrón, M. (2008). Cultura y valores de los estudiantes de Contaduría Pública. Instituto Mexicano de Contadores Públicos. https://bit.ly/3g|Yzs]

Salgado, J. (2016). Abordaje de la cultura desde la investigación en contabilidad: posibilidades de re-significación. Revista Facultad de Ciencias Económicas, 14(1), 103-118. https://bit.ly/33JJLyP

Splitter, K., \& Borba, J. (2014). Percepción de Estudiantes y Profesores Universitarios sobre la Profesión del Contador: un Estudio Basado en la Teoría de los Estereotipos. Revista de Educação e Pesquisa em Contabilidade, 8(2), 126 141. https://bit.ly/37yNu3s
Torres, C., \& Wong, L. (2012). Los fundamentos epistemológicos de la contabilidad y su incidencia en la formación competitiva del contador público. Sotavento M.B.A., 19, 32-50. https://bit. ly/3qtAq8c

Valero, G. (2000). La contabilidad y el cine: Una experiencia pedagógica para la formación del Contador Público [ponencia]. XIII Asamblea General de ALAFEC. https://bit.ly/3IGHWt

Varela, C., \& Novoa, R. (2017). Imaginario social del contador público en el cine. Revista Visiones, (17), 126-140. https:// bit.ly/2JR1XZJ

Vargas, R., Cruz, E., Gatica, L. (2015). El Contador Público como líder del cambio social en el nuevo escenario educativo mexicano. Revista Iberoamericana de Ciencias, 2(4), 167-177. https://bit. ly/36FRksj 